\title{
Pre-Excitation Syndrome
}

National Cancer Institute

\section{Source}

National Cancer Institute. Pre-Excitation Syndrome. NCI Thesaurus. Code C34940.

An electrocardiographic finding characterized by a premature activation of the whole or some part of the ventricle. The PR interval is usually shortened and delta waves are frequently present. (CDISC) 